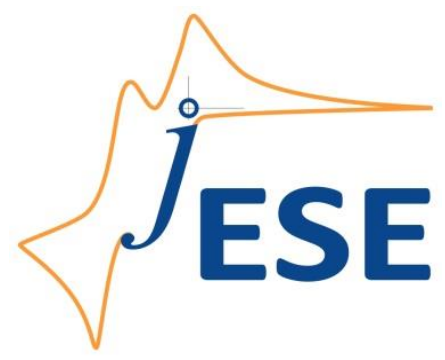

Open Access: ISSN 1847-9286

www.jESE-online.org

Review

\title{
Electrokinetics and soil decontamination: concepts and overview
}

\author{
Mohammed A. Karim \\ Department of Civil and Construction Engineering, Southern Polytechnic State University (SPSU), \\ 1100 South Marietta Parkway, Marietta, Georgia 30060, USA \\ E-mail: mkarim@spsu.edu \& makarim@juno.com, Phone: (678) 915-3026 (Off.); (804) 986-3120 \\ (Cell)
}

Received: February 12, 2014; Revised: May 17, 2014; Published: December 6, 2014

\begin{abstract}
Electrokinetic decontamination and extraction have been proven to be one of the most viable, cost effective and emerging techniques in removing contaminants, especially heavy metals from soils for about last five decades. Basic concepts and an overview of the electrokinetic extraction processes and their potential applications in geotechnical and geoenvironmental engineering have been reviewed based on the literature and presented in this paper. Primarily, theoretical and laboratory experimental studies related to electroreclamation of soils are summarised in brief with basic concepts of electrokinetic processes. The paper has been divided into different sections that include history of electrokinetics, background and concepts, modelling, parameter effects, instrumentation, contaminant extraction, field applications, and summary and recommendation. Based on the review it is obvious that the field application of electrokinetic technology to remediate heavy metal contaminated soils /sediments is very limited and site specific. Additional laboratory studies and more pilot- and full-scale information from field applications are critical to the further understanding of the technology and to customize the process in different field conditions.
\end{abstract}

\section{Keywords}

Electrokinetic decontamination; heavy metals; site remediation; soil; EDTA; soil pH; electro-osmosis; electrophoresis; streaming potential; ion migration; sediment potential; zeta potential; electrolysis; electrokinetic modelling

\section{Introduction}

Contaminant such as heavy metals removal from solid porous medium such as soils and sediments has been a technological challenge for engineers and scientists for the past several decades. A variety of remedial options exist to cleanup a hazardous waste site; however, the 
technological challenge, efficiency, and costs of these options may vary widely. Conventional ground burial and land disposal are often economical, but they do not provide a permanent solution, and in some cases they are not necessarily the most effective solutions. For removing contaminants such as organics and inorganics from solid porous media, the most common ex-situ methods employed include soil washing, and ligand extraction. Ex-situ methods may not be technologically challenged that much; however, they suffer from several problems. Apart from the generic problems of any ex-situ process, i.e., the need to excavate the media and place it in an external reactor, the above mentioned processes suffer from several disadvatages [1].

Several in situ methods include vacuum extraction, thermal desorption, hydraulic fracturing, electrokinetic decontamination (including the "Lasagna" process), biotreatment, immobilization by encapsulation, and placement of barrier systems are already in use to some extent for soil and sediment remediation and decontamination. Most of these processes are employed for removal of organics present in soils or sediments. Among these in-situ methods electrokinetic decontamination (EKD) processes are in use for the past five decades in different applications. The major advatages of the EKD processes include (a) they can be implemented in-situ with minimal disruption, (b) they are well suited for fine-grained, heterogenous media, where other processes can be ineffective, and (c) accelerated rates contaminant extraction and transport may be achieved. The basic concepts and an overview of the EKD processes and their real life applications, as of now, in geotechnical and geoenvironmental engineering have been reviewed and presented in this paper. Primarily, theoretical and laboratory experimental studies related to EKD of soils and sediments are presented in brief with basic concepts of electrokinetic processes.

\section{History}

The movement of water through capilary and pores as a result of the application of electric potential is known as electrokinetic phenomena and this phenomena was first described by $F$. F. Reuss in Russia in 1808. This phenomenon was first treated analytically by Helmholtz in 1879, which was later modified by Pellat in 1903 and Smoluchowski in 1921. This phenomenon is widely known as the Helmholtz-Smoluchowski model which relates electro-osmotic velocity of a fluid of certain viscosity and di-electric constant, through a charged porous medium under an electric gradient. The Helmholtz-Smoluchowski model is the most common theoretical description of electro-osmosis and is based on the assumption of fluid transport in the soil or sediment pores due to transport of the excess positive charge in the diffuse double layer towards the cathode [2]. It applies to systems with pores that are large relative to the size electric diffuse double layer and provides with reasonable predictions for electro-osmotic flow in most soils. The rate of electroosmotic flow is controlled by the coefficient of electro-osmotic permeability of porous media and the balance between the electrical force on the liquid and the friction between the liquid and the surface of the particles of the porous media. The first application of electrokinetics was made by Casagrande in 1939 for consolidation and stabilization of soft fine-grained soils. Numerous laboratory studies and a very few field applications have been conducted to investigate the electrokinetic processes to date. The areas in which electrokinetics have been applied successfully to some extent include increasing pile strength, stability of soil during excavation and embankments, increasing flow rate of petroleum production, removal of salts from agricultural soils, removal of metalic objects from the ocean bottom, injection of grouts, microorganisms and nutrients into the subsoil strata of low permeability, barriers and leak detection systems in clay liners, dewatering of clayey formations during excavation, control and decontamination of 
hazardous wastes, removal of chemical species from saturated and unsaturated porous medium, removal of gasoline hydrocarbons and trichloroethylene from clay and removal or separation of inorganic and organic contaminants and radionuclides.

\section{Background and Concepts}

Electrokinetic processes are a relatively new and promising technology being investigated for their potential applications in hazardous waste management specifically in case of high clay containing soils. United State Environmental Protection Agency (USEPA) has designated electrokinetic method as a viable in-situ process and interested parties are attempting to apply this method at contaminated sites which have inherently low permeability soils and otherwise difficult to decontaminate. Electrokinetic flows occur when an electric gradient is applied on a soilfluid-contaminant system due to existence of the diffuse double layer at the soil particle surface pore fluid interface. Several electrokinetic phenomena arise in clay when there are couplings between hydraulic and direct current (DC) electrical driving forces and flows. Those phenomena can broadly be classified into two pairs by the driving forces causing the relative movement between the liquid and the solid phases. The first pair consists of electro-osmosis and electrophoresis, where the liquid or the solid phase moves relative to the other under the influence of an imposed electrical potential. The second pair consists of streaming potential and migration or sedimentation potential, where the liquid or the solid phase moves relative to the other under the influence of hydraulic or gravity force and thus inducing an electrical potential. Those four electrokinetic phenomena in clay are depicted in Fig. 1 [3].

Electrical gradient induces water flow

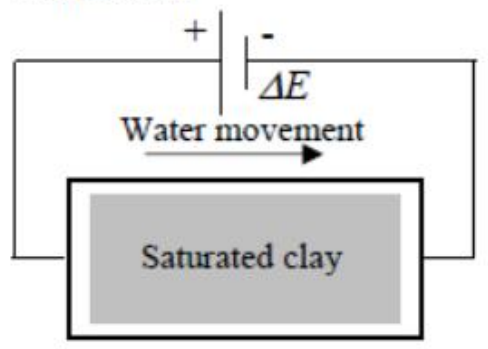

Electroosmosis

Water flow induices electric potential

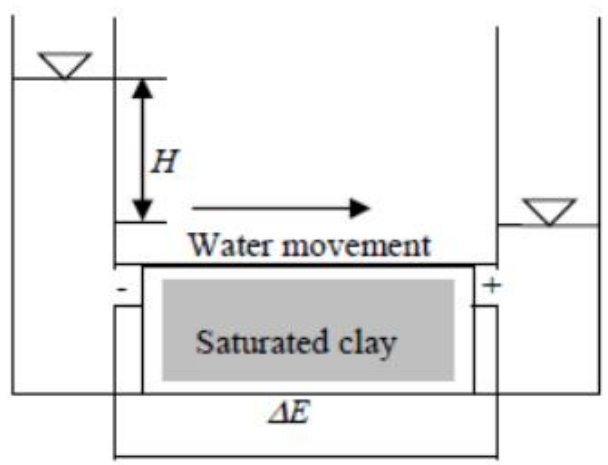

Streaming potential
Electric gradient induces particle movement

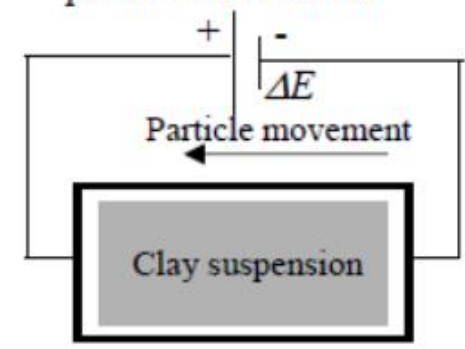

Electrophoresis

Particle movement generates electric potential

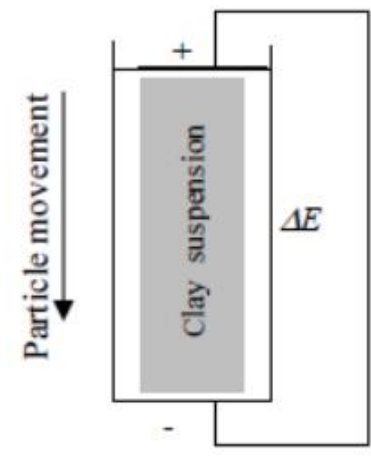

Migration or sediment potential

Fig. 1. Electrokinetic phenomena in clay 
The detailed description of these flow processes and the associated complicated features generated by electrochemical reactions are given by several authors [4-23]. The use of electrokinetics in sealing leaks in geomembrane and compacted clay liners has been explained in detail by a few authors [24-28]. Potential applications of electrokinetics in geotechnical and geoenvironmental engineering are described elaborately by multiple authors [21,22,27,29,30-34]. Some of the applications, as appropriate, are reviewed and included in the subsequent sections.

The extraction technique, variably called electrokinetic remediation, electroremediation, electroreclamation, electrorestoration, electrochemical soil processing or electrochemical decontamination, uses low level constant voltage DC power supply, potential gradients in the range of 20-200 $\mathrm{V} \mathrm{m}^{-1}$ [35] or alternatively a constant current density in the range of $0.025-5 \mathrm{~A} \mathrm{~m}^{-2}$ [31] between the electrodes placed at the end of the contaminated soil sample. When an electric field is imposed to a wet soil mass, positive ions are moved toward the cathode (the negative electrode) and the negative ions toward the anode (positive electrode) as illustrated in Fig. 2 [36]. Because of the isomorphous substitution and the presence of broken bonds in the soil structures, excess mobile cations are required to balance the negative fixed charges on the soil particle surfaces. Therefore, mobile cations exert more momentum to the pore fluid than do mobile anions. As a result there is a net movement of fluid relative to soil particles under the influence of imposed electric potential gradient which is called electro-osmosis (field-induced convection of water through a porous medium with a surface charge). Unlike water flow under pressure, electro-osmosis depends on the electric current through the soil, the flow resistance of soil, and the frictional drag exerted by the migrating ions in the water molecule and this flow originates at the electric double layer of the soil pores. The electrokinetic flow rate $q_{\mathrm{eo}}$ in a porous medium of length $L$, porosity $n$, area $A$ and degree of saturation $S$, may be presented by the following equation [37]:

$$
q_{\mathrm{eo}}=\frac{\psi_{\mathrm{d}} \varepsilon_{\mathrm{o}} D}{\eta} I_{\mathrm{s}} \frac{R_{\mathrm{s}}}{L} n A S
$$

where $\psi_{\mathrm{d}}$ is the potential at the slipping plane, $\varepsilon_{\mathrm{o}}$ is the permeability of free space, $D$ is the dielectric constant of the pore fluid, $\eta$ is the pore water viscosity, $I_{\mathrm{s}}$ is the current carried by surface conductance and $R_{\mathrm{s}}$ is the surface resistance of the porous medium i.e. soil.

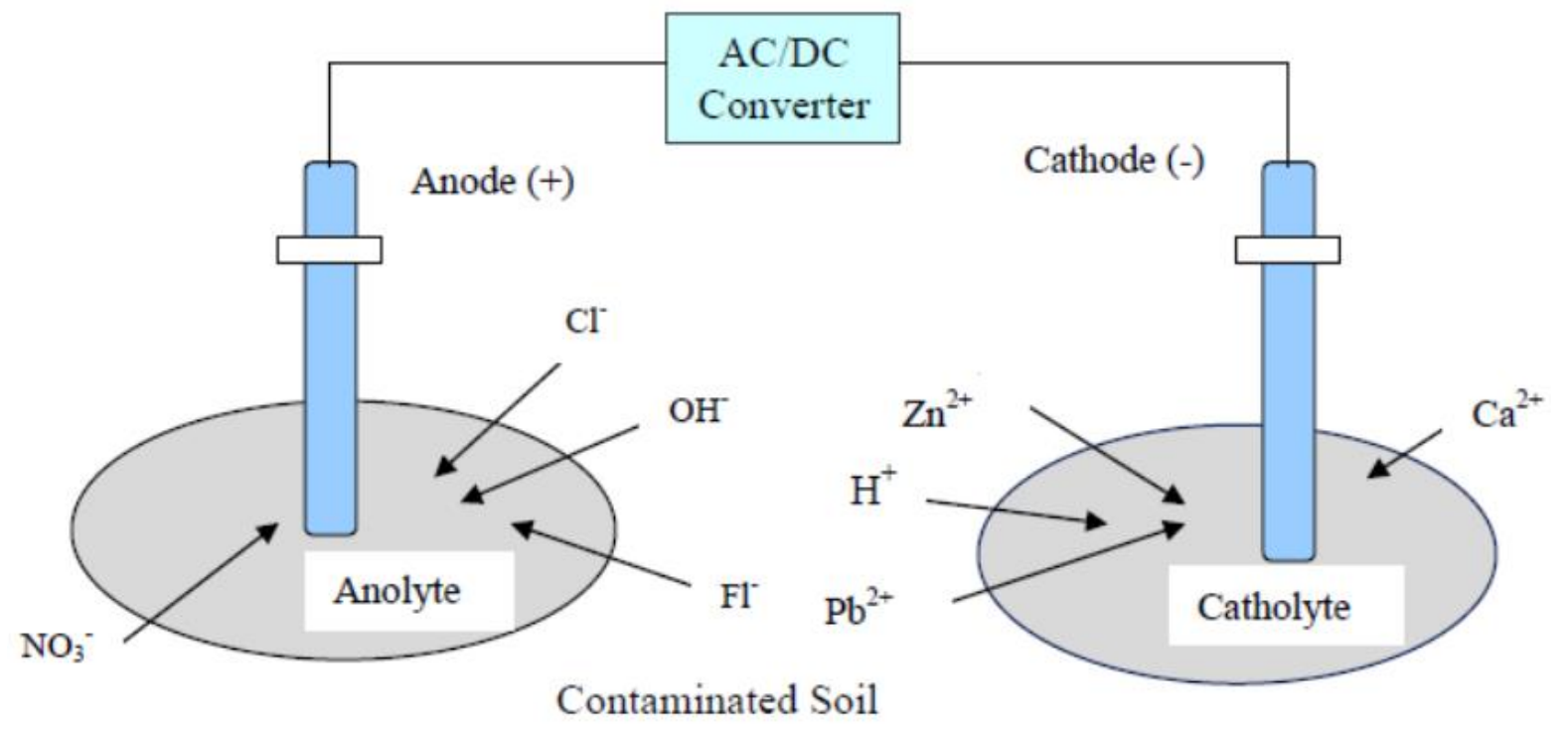

Fig. 2. Concept of electrokinetic extraction of contaminants 
When the electrokinetic technique is applied without conditioning of the process fluid at the electrodes, which is termed as unenhanced electrokinetic remediation, the applied electric current leads to electrolysis reactions at the elctrodes, generating an acidic medium at the anode and an alkaline medium at the cathode [38]. The electrolysis reactions of the primary electrodes are presented in the following equations:

Anode Reaction: $2 \mathrm{H}_{2} \mathrm{O}-4 \mathrm{e}^{-} \Rightarrow \mathrm{O}_{2} \uparrow+4 \mathrm{H}^{+}, \quad E^{\circ}=-1.229 \mathrm{~V}$

Cathode Reaction: $2 \mathrm{H}_{2} \mathrm{O}+2 \mathrm{e}^{-} \Rightarrow \mathrm{H}_{2} \uparrow+2 \mathrm{OH}^{-}, \quad E^{\circ}=-0.828 \mathrm{~V}$

where $E^{\circ}$ is the standard reduction electrochemical potential, which is a measure of the tendency of the reactants in their standard states to proceed to products in their standard states. Although some secondary reactions might occur at the cathode because of their lower electrochemical potential, the water reduction half reaction $\left(\mathrm{H}_{2} \mathrm{O} / \mathrm{H}_{2}\right)$ is dominant at early stages of the process. Within the first few days of the process, electrolysis reaction drops the $\mathrm{pH}$ at the anode below 2 and increases the $\mathrm{pH}$ at the cathode above 10, depending the total current applied [9]. The following are the secondary reactions that may exist depending upon the concentration of available species:

$$
\begin{aligned}
& \mathrm{H}^{+}+\mathrm{e}^{-} \Rightarrow(1 / 2) \mathrm{H}_{2} \uparrow \\
& \mathrm{M}^{\mathrm{n}}+\mathrm{ne}^{-} \Rightarrow \mathrm{M} \\
& \mathrm{M}(\mathrm{OH})_{\mathrm{n}}(\mathrm{s})+\mathrm{ne}^{-} \Rightarrow \mathrm{M}+\mathrm{nOH}^{-}
\end{aligned}
$$

where $\mathrm{M}$ refers to metals. The acid medium (Eq. 2) generated at the anode advances through the soil toward the cathode by ionic migration and electro-osmosis due to electrical gradient, pore fluid flow due to any externally applied or internally generated hydraulic gradient and diffusion due to the chemical gradients developed in the system. The base developed at the cathode initially advances toward the anode by diffusion and ionic migration. However, the counterflow due to electro-osmosis retards the back-diffusion and migration of the base front. The advance of this front is slower than the advance of the acid front because of the counteracting electro-osmotic flow and also because the ionic mobility of $\mathrm{H}^{+}$is about 1.76 times that of $\mathrm{OH}^{-}$. As a result, the acid front dominates the chemistry across the specimen except for small section of the specimen close to the cathode, where base front prevails [21,35]. As the acid buffer capacity of soil or sediment is low, acid front moving through the soil lowers the system $\mathrm{pH}$. Since most heavy metals are soluble in an acidic environment, this lowering of $\mathrm{pH}$ promotes desorption of heavy metals from the soil and solubilization of metal ions. Ions in dissolved phase can be removed effectively by the combined actions of electro-osmosis and ion migration. However, the presence of heavy molecular weight organic matter (humus substances) within the soil pores may reduce the mobility of the heavy metals due to the formation of organometallic compounds. Under these circumstances, enhanced electrokinetic remediation could be necessary. Numerous studies have been conducted to date using different chelating and complexation agents to enhance the remedial techniques [39-52]. The particular use of the enhancing and conditioning agents are reviewed and included in the appropriate sections.

\section{Modeling electrokinetics}

Electrokinetic modeling is based on the applicability of coupled flow phenomena for fluid, solute, current and temperature flow through porous media under the influence of hydraulic, 
electrical, concentration, and thermal gradients, respectively. The governing equations for these analyses generally have been formulated on the basis of the postulates of irreversible thermodynamics and the applicability of the Onsager reciprocal relations under the assumption of isothermal conditions [14,16], although equation formulation on the basis of continuity considerations has also been shown $[53,54]$. The state-of-the-art in modeling electrokinetic remediation is represented by the one-dimensional finite element model for coupled multicomponent, multispicies transport under electrical, chemical and hydraulic gradients described in a study conducted by Alshawabkeh and Acar [54]. This study compared the predictions of $\mathrm{Pb}$ removal using the model with the results of pilot scale study involving electrokinetic extraction of $\mathrm{Pb}$ from a spiked kaolinite sand mixture. Multidimensional models for multi spices transport have been developed by several reserachers [55-57]. A study conducted by Haran et al. [58] developed a mathematical model for decontamination of hexavalent chromium from low surface charged soils. They simulated the concentration profiles for the movement of ionic species under a potential field for different time period. The model predicted the sweep of the alkaline front across the cell due to the transport of $\mathrm{OH}^{-}$ions. A comparison of chromate concentration profiles with experimental data for 28 days of electrolysis showed a good agreement. A numerical model of transport and electrochemical processes was extended for the first time to incorporate complexion and precipitation reactions in a study by Jacobs et al. [59]. Their model confirmed that the isoelectric focusing could be eliminated and high metal removal efficiencies could be achieved by washing the cathode. In order to describe the transport and reaction processes in a porous medium in electrical field, one-dimensional numerical models have been developed by several authors [60-62]. In several studies, Choi and Lui [63-66] developed a mathematical model for the elctrokinetic remediation of contaminated soils assuming the contaminants are mostly heavy metals, water is in excess, the dissociation-association of water into hydrogen and hydroxyl ions is rapid, and that electro-osmosis is significant when compared to electromigration (field-induced transport of ions in an electrolyte as defined earlier) as a transport mechanism. The analytical steady state solutions of electroplating and transport in binary electrolyte arising from electrochemistry were provided in several articles by several authors [67-70]. Electrolysis and isoelectric focusing effects were also theoretically analyzed by various researchers [68-71]. Modified finite difference model of electrokinetic transport in porous media was developed and numerical solutions were provided in studies [60,72]. An assessment of available multispecies transport model and an investigation of long-time behavior of multi-dimensional electrophoretic models were done in couple of studies $[9,73]$. The quantitative determination of potential distribution in Stern-Gouy double layer model was elaborated by Shang et al. [74]. The analytical and numerical steady state solutions for electrochemical processes with multiple reacting species were provided in articles [75,76]. Shackelford [77] summarized the modeling electrokinetic remediation. In his review he emphasized that the prediction of multi-component, multi-species transport with chemical reactions through soil medium represents one of the challenging modeling endeavors in environmental geotechnics. He compared his statement with studies conducted by Acar and Alshawabkeh [78] and mentioned that this study provided some insight of the advances along these lines. However, he stressed on the additional effort that is needed in evaluating the potential limitations in modeling these electrokinetic processes in terms of the assumptions inherent in the models and field-scale applications. 


\section{Instrumentation}

Electrokinetics has many applications in geo-environmental and geotechnical engineering. For the measurements of electrokinetic properties of soil and soil remediation processes, individual researchers have designed their own apparatuses of various shapes, sizes and materials for different purposes. Some significant experimental apparatuses used for geotechnical and geoenvironmental engineering investigation have been reviewed in detail by Yeung [13]. A number of important apparatuses that have been used for soil remediation by electrokinetics are mentioned here. The apparatuses currently available for the purpose of electrokinetic remediation include those developed at Louisiana State University [31,79], Lehigh University [52,80,81], University of Texas at Austin [11,82], the University of California at Berkeley [3,83], Massachusetts Institute of Technology [38, 47, 59], Texas A \& M University [6], The Technical University of Denmark [84,85], Vanderbilt University, Nashville, Tennessee [86], Royal Institute of Technology, Stockholm, Sweden [87-89], University of South Carolina [58] and many others. A comprehensive review of the apparatus used in the EKD experiments has been presented by Yeung et al. [6]. However, it is obvious from the literature that most of these apparatuses are used for the remediation of finegrained soils by electro-osmosis. None of them except the last three are used for the decontamination of course-grained soils such as sandy/salty soils, where the electro-osmosis is ineffective [90]. It is reported that the last two instruments have been successfully used to decontaminate sandy soils using electrolysis and electro-migration.

\section{Parameter Effects}

The important parameters of EKD processes are electric gradient, system $\mathrm{pH}$, electro-osmotic flow, ion-migration, zeta potential, electro-osmotic permeability, and current density. All of these parameters play important role in the process efficiency, soil decontamination, and ultimately the cost. Therefore, parameter optimization should be an important part the process performance. In general, the application of electric gradient induces electric current density and promotes the electrolysis reactions at anode and cathode. Electric current results in generation of protons $\left(\mathrm{H}^{+}\right)$ at the anode (Eq. 2) that migrate together with the metal cations to the negatively charged cathode (Fig. 2) for removal and processing. A very low voltage can serve the purpose of electrolytic reactions and create low $\mathrm{pH}$ solution in the anode. So determination of optimum electric gradient or current density is important as higher electric gradient or current density may increase the cost of the process and create higher gases in anode and cathode which may require careful watch and become difficult to maintain experiments. Electro-osmotic flow is the prevalent parameter for the low permeable soils having high surface charges whereas ion-migration may be the driving force for high permeable soils having low surface charges. System $\mathrm{pH}$ contributes to the dissolution of metal precipitates and depends on the type of contaminants and their salts present in the soils. Most of the metal salts may be soluble in a $\mathrm{pH}$ range of 2 to 4 . Therefore, bringing the soil $\mathrm{pH}$ below 2 may not be necessary to optimize the removal efficiency.

It is reported that the values of hydraulic conductivity of different soils can differ by orders of magnitude; however, those of coefficients of electro-osmotic conductivity are generally between $1 \times 10^{-5}$ and $10 \times 10^{-5} \mathrm{~cm}^{2} \mathrm{~V}^{-1} \mathrm{~s}^{-1}$ and are relatively independent of soil type. Thus, an electric gradient is much more effective driving force than a hydraulic gradient for moving fluid through fine-grained soils of low hydraulic conductivity $[6,9,83$ ]. Korfiatis et al. [91] used an experimental approach to assess the relative magnitudes of hydraulic and electro-osmotic permeability under application of hydraulic or electric gradients or both and to study the extent of $\mathrm{pH}$ changes during 
the electro-osmotic process. The practical and theoretical aspects of ion exchange resins and membranes have been investigated by Hansen [85,92]. Acar et al. [30] estimated the electroosmotic permeability in kaolinite to be in the range of $0.80 \times 10^{-5}$ to $3.0 \times 10^{-5} \mathrm{~cm}^{2} \mathrm{~V}^{-1} \mathrm{~s}^{-1}$ which is within the range reported in the literature.

The zeta potential of most soils, except for quartz, is negative, because soil surfaces carry a negative charge that causes the electro-osmotic generally from anode to cathode. The $\mathrm{pH}$ and ionic strength of the pore fluid may affect the value of zeta potential and zeta potential is reported to decrease linearly with logarithm of the $\mathrm{pH}$ of the porous medium [2]. High acidic solution causes the zeta potential to become less negative and even to attain positive values at low $\mathrm{pH}$. As a result flow rates have been reported to decrease if the $\mathrm{pH}$ of the electrolyze is depressed below neutral and to increase at alkaline $\mathrm{pH}$ values $[47,93]$. The effect of zeta potential on electro-osmotic permeability has further been investigated by Shang [94].

The steady state and limiting current conditions are investigated by Dzenitis [95]. Influence of current density and system pH on electro-remediation of kaolinite clay was investigated by Rahman [45] and Hamed and Bhadra [93] and soil saturation effect on electrorestoration was investigated by Puppala [46]. The effects of temperature on electrokinetic remediation on low permeability soils are explored by Penn [96]. The effects of electrokinetics in complex natural sediments are explained by Grundl and Reese [97]. Shang et al. [98] investigated the effects of polarization and conduction on clay-water-electrolyte systems. Shri Ranjan and Karthigesu [99] devised a capillary flow meter for measuring the hydraulic conductivity of clay under the applications of low gradients. A theoretical and experimental basis on electrokinetic sedimentation is explained by Shang [5]. Reddy et al. [100] investigated the effects of soil composition on the electrokinetic extraction of chromium (VI). They used three kinds of soil minerals such as kaolin, glacial till, and Na-montmorillonite in their study. Their study found that the adsorption and removal of $\mathrm{Cr}(\mathrm{VI})$ are greatly dependent on the compositions of the soil minerals.

\section{Contaminant extraction}

There are some cases where unenhanced electrokinetic extraction is ineffective for soil remediation. In this situation chelating and conditioning agents are used to enhance the process which is termed as enhanced electrokinetic remediation. The most commonly used chelating and conditioning agents are Ethylene diamine tetraacetate (EDTA), $\mathrm{HCl}$, acetic acid, iodine-iodide etc. A few important studies using enhanced and unenhanced electrokinetic process have been reviewed and presented below. However, only the studies related to heavy metal removals were reviewed and reported here.

\section{Heay Metal Removal with Enhanced Process}

In a study conducted by Cameselle and Reddy [101] found that electro-osmotic flow under applied electric potential depends on a number of soil, contaminant and applied electric potential conditions. Electro-osmotic flow induced in the same direction of metal or complexed metal ions transport can enhance heavy metal removal. In case of hydrophobic organic contaminants, periodic voltage application combined with the use of a solubilizing solution is shown to create sustained electro-osmotic flow and enhanced contaminant removal. The suggested to validate the optimum conditions determined from laboratory investigations for generating significant electroosmotic flow through field pilot-scale demonstrations. Joseph et al. [41] investigated the feasibility 
of mobilizing precipitate heavy metals from soil by ionic migration using EDTA. They used EDTA solution to catholyte where it solubulizes the precipitated metals. The resulting complexes are then transported to the anode. The removal efficiencies were found to be very close to $100 \%$ for $\mathrm{Zn}$ and $\mathrm{Pb}$. A feasibility study of using surfactants and organic acids sequentially and vice versa during EKD was evaluated by Reddy et al. [102] for removal of both heavy metals and PAHs from clayey soils. They selected kaolinite as a model clayey soil and spiked it with phenanthrene and nickel at concentrations of $500 \mathrm{mg} \mathrm{kg}^{-1}$ dry each to simulate typical field mixed contamination. They performed bench-scale electrokinetic experiments with the sequential anode with $1 \mathrm{M}$ citric acid followed by $5 \%$ Igepal CA-720, $1 \mathrm{M}$ citric acid followed by $5 \%$ Tween 80 , and $5 \%$ Igepal CA-720 followed by $1 \mathrm{M}$ citric acid. The migration and removal efficiency of panathrene in the first two sets of tests were found to be very low. But overall the sequential use of $5 \%$ Igepal CA 720 followed by $1 \mathrm{M}$ citric acid appeared to be an effective remedial strategy to remove coexisting heavy metals and PAHs from clayey soil. The effect of EDTA in removing Pb and $\mathrm{Zn}$ from millpond sludge during EKD was investigated by Karim and Khan [39]. They conducted several experiments with distilled water and dilute EDTA solutions with strengths of $0.05 \mathrm{M}$ and $0.125 \mathrm{M}$. The beneficial effects of using EDTA that were observed in this investigation are EDTA substantially increased the electro-osmotic flow in the millpond sludge indicating that it could significantly reduce the duration of EKD, a significantly higher percentage of $\mathrm{Pb}$ and $\mathrm{Zn}$ removal from the solid phase due to the complexation of EDTA with these heavy metals, and EDTA was able to prevent the precipitation of metals near the cathode electrode typically observed in EKD process. Yeung et al. [103] studied the basic Pb-EDTA complexion reactions and their influence on electrokinetic extraction process. Their main focus was on EDTA enhanced electrokinetc extraction of lead from Milwhite and Georgia kaolinite and the acid/base buffer and sorption capacities of these soil minerals. Their study revealed that more than $90 \%$ of lead was migrated toward the cathode with a lower voltage applied across the sample within a shorter duration of treatment. Allen and Chen [48] investigated the extraction of lead from the contaminated New Jersey and Delaware soils with EDTA. The investigation found almost $100 \%$ extraction of lead from New Jersey soil at a $10^{-3} \mathrm{M}$ concentration of EDTA and at $10^{-3} \mathrm{M}$ or lower concentration of EDTA, the recovery of lead that had been added to the Delaware soil was greater than that of New Jersey soil that had been previously contaminated at level of $\mathrm{pH} 4.3 \pm 0.1$. Li et al. $[88,89]$ suggested a new approach in electrokinetic decontamination in which a conductive solution was inserted between the cathode and the soil to be treated. By this approach, the $\mathrm{pH}$ in the soil can be kept low so that no metal precipitation would occur near the cathode. This would eliminate the isoelectric focusing effect. Their study found the metal removal efficiencies of more than $96 \%$ for both copper and zinc. A similar approach was suggested by Shapiro et al. [104] in which acetic acid was used to rinse the catholyte to reduce the $\mathrm{pH}$ near cathode. Cox et al. [105] studied the remediation of mercury from soils using iodine-iodide as a chelating agent and found it to be very effective. Acar and Alshawabkeh [78] investigated the feasibility and efficiency of transporting $\mathrm{Pb}$ under an electric field with a constant current. The tests were conducted with a Pb concentration of $856 \mathrm{mg} \mathrm{kg}^{-1}$ and $1,553 \mathrm{mg} \mathrm{kg}^{-1}$ respectively. The third test was conducted on a 1:1 mixture of kaolinite and sand with $\mathrm{Pb}$ concentration of $5,322 \mathrm{mg} \mathrm{kg}^{-1}$. Their study found that $55 \%$ of $\mathrm{Pb}$ mobilized inside the soil precipitated within the last $2 \mathrm{~cm}$ close to the cathode, 15\% were left in the soil before reaching this zone, $20 \%$ precipitated on the fabric separating the soil from cathode, and $10 \%$ were unaccounted. Ellis et al. [106] studied the release of cadmium, chromium, copper, lead, and nickel from soil collected from a Superfund site near Seattle, Washington. They conducted both batch 
equilibrium and column studies using EDTA alone and EDTA followed by hydroxylamine hydrochloride, to reduce iron oxides in the soil. Results of their batch and column tests showed that EDTA was able to remove more than $90 \% \mathrm{~Pb}$ and $60 \% \mathrm{Cd}$. Huang et al. [107] found that the removal of $\mathrm{Zn}$ (II) from solids is independent of types of solids. The addition of EDTA resulted in a shift of maximum $\mathrm{Zn}$ (II) adsorption to the acidic $\mathrm{pH}$ range, and reduction of zeta potential and overall $\mathrm{Zn}$ (II) removal in presence of EDTA was significantly reduced at alkaline $\mathrm{pH}$ range and slightly enhanced in the acidic range. Klewick and Morgan [108] explored the rates of decomposition of complexes for Manganese in the +III oxidation state as a function of the complexing ligand, the total ligand: manganese concentration ratio and the $\mathrm{pH}$. Three ligands were chosen, EDTA was one of them. The rate of appearance of the Mn (III) complex decreased with increasing $\mathrm{pH}$ over the range of 6 to 8. McArdell et al. [109] studied cobalt-EDTA complexation generated on site at Oak Ridge, TN shallow landfills. Their study confirmed the ability of EDTA to solubilize mineral surface-bond Co (III). Davis and Singh [110] studied the several chemical washing procedures for $\mathrm{Zn}$ (II) contaminated soil to determine the metal extraction efficiency from using specific extractants such as acid solution, EDTA, diethylenetriamine pentaacetic acid (DTPA), and Chlorine. Their study found $79 \%$ removal of Zn(II) with 0.001 M EDTA, $85 \%$ with 0.003 M EDTA for $\mathrm{pH}$ around 2; $79 \%$ with $0.001 \mathrm{M}$ DTPA, 90\% with $0.003 \mathrm{M} \mathrm{DTPA}$ for a pH of 2, and $85 \%$ with $0.003 \mathrm{M} \mathrm{DTPA}$ for a pH of 6 . They also found that about $99 \%$ of $\mathrm{Zn}$ (II) was in the form of Zn-EDTA complex at $\mathrm{pH}$ level 6 . Amrate et al. [111] tested the removal of lead from an Algerian contaminated soil (with $\mathrm{Pb}$ concentration $\approx 4.43 \mathrm{mg} / \mathrm{g}$ of soil) sited near a battery plant using EDTA at various concentrations $(0.05-0.20 \mathrm{M})$. They applied a constant voltage corresponding to nominal electric field strength of $1 \mathrm{~V} \mathrm{~cm}^{-1}$ for duration of 240 hours. Results of contaminant distribution across the experimental cell have shown efficient transport of lead toward the anode despite the presence of calcite $(25 \%)$ and the high acid/base buffer capacity of the soil. They modified the cell by adding extra compartments and inserting cation exchange membranes (Neosepta CMX) to avoid ligand loss, which would be anodically oxidized. They found simultaneous recovery of EDTA and lead from their chelated solutions. Reddy et al. [112] conducted batch and electrokinetic experiments to investigate the removal of three different heavy metals, chromium (VI), nickel (II), and cadmium (II), from a clayey soil by using EDTA as a complexing agent. Their batch experiments revealed that high removal of these heavy metals (62-100\%) was possible by using either a $0.1 \mathrm{M}$ or $0.2 \mathrm{M}$ EDTA concentration over a wide range of $\mathrm{pH}$ conditions (2-10). However, the results of the electrokinetic experiments using EDTA at the cathode showed low heavy metal removal efficiency. They used EDTA at the cathode along with the $\mathrm{pH}$ control at the anode with $\mathrm{NaOH}$ which increased the $\mathrm{pH}$ throughout the soil and achieved high (95\%) $\mathrm{Cr}(\mathrm{VI})$ removal, but the removal of $\mathrm{Ni}$ (II) and $\mathrm{Cd}$ (II) was limited due to the precipitation of these metals near the cathode. Their finding was that the low mobility of EDTA and its migration direction, which opposed electro-osmotic flow, prevented EDTA complexation from occurring. They also found many complicating factors that affected EDTA-enhanced electrokinetic remediation and suggested further research to optimize this process to achieve high contaminant removal efficiency.

\section{Heay Metal Removal with Unenhanced Process}

A comprehensive treatise on removal of $\mathrm{Pb}$ (II) from kaolin is reported by Hamed [34] and Hamed et al. [79]. The process removed about $75 \%$ to $95 \%$ of $\mathrm{Pb}$ (II) at concentrations up to $1500 \mu \mathrm{g} \mathrm{g}^{-1}$ across the test specimen at a energy expenditure of 29-60 $\mathrm{kWh} \mathrm{m}^{-3}$ of soil processed. Li et al. [88] examined the efficiency of electro-migration process in removing $\mathrm{Pb}$ (II), $\mathrm{Cd}$ (II) and 
$\mathrm{Cr}$ (III) from sandy soils. Their study showed the removal efficiencies more than $90 \%$ for all three metals. Hamed and Bhadra [93] studied the effect of current density and influent $\mathrm{pH}$ on electrokinetic processing. Their study results revealed that flow rate increases as the current density increases and the electro-osmotic flow increases gradually between $\mathrm{pH}$ of 2 to 10 and sharply between $\mathrm{pH}$ of 10 to 12. Acar and Alshawabkeh [78] investigated the feasibility and efficiency of transporting lead under electric field conducting three pilot-scale tests with leadspiked kaolinite at an electrode spacing of $72 \mathrm{~cm}$. In their tests program, a constant current of density $133 \mu \mathrm{A} \mathrm{cm}{ }^{-2}$ was applied. Out of three tests, two of them were conducted with a lead concentration of $856 \mathrm{mg} \mathrm{kg}^{-1}$ and $1,533 \mathrm{mg} \mathrm{kg}^{-1}$ respectively. The third test was conducted on a $1: 1$ mixture of kaolinite and sand with lead concentration of $5,322 \mathrm{mg} \mathrm{kg}^{-1}$. Their study found that $55 \%$ of lead removal across the soil precipitated within the last $2 \mathrm{~cm}$ close to the cathode, $15 \%$ left in the soil before reaching this zone, $20 \%$ precipitated on the fabric separating the soil from cathode and $10 \%$ unaccounted. Hansen et al. [84] investigated the removal of $\mathrm{Cu}, \mathrm{Cr}, \mathrm{Hg}, \mathrm{Pb}$ and Zn from sandy loam by electrodialysis. Their study found that decontamination of soil was to an extent lower than the recommended critical values for metal concentration in soil. The elctrochemical analysis of ion-exchange membrane with respect to a possible use in electrodialytic decontamination of soil polluted with heavy metals was also studied by Hansen et al. [85]. Their study revealed that cation-exchange membranes show the transport number of average 0.97 in $\mathrm{NaCl}$ and $\mathrm{CaCl}_{2}$ solutions and anion-exchange membranes about 0.95 in $\mathrm{NaCl}, \mathrm{CaCl}_{2}$ and $\mathrm{ZnCl}_{2}$ solutions. One-dimensional experimental studies were conducted by Yeung et al. [113] and Darilek et al. $[27,28]$ to examine the feasibility of using electrophoresis to repair in-service leaking surface impoundment lined by geomembranes. Their studies were concentrated on the effect of clay type, clay particle concentration in the suspension and the electric field strength on the cake formation mechanism. Acar et al. [114] investigated the removal of Cd (II) from saturated kaolinite under the application of electric current and found to remove more than $95 \%$ of $\mathrm{Cd}$ (II) within 10 days of experiment. The effect of various sites and operating conditions on the efficacy of metal removal by electromigration was investigated by Hicks and Tondorf [38] and Pamukcu and Wittle [81]. Pamukcu et al. [52] investigated the feasibility of electro-osmosis to remove zinc from soil since it was listed among the 129 priority pollutants by EPA and is known to possess moderate noncarcinogenic toxicity and is found frequently in the soil in contaminated sites. Their finding was encouraging in zinc migration to the cathode chamber. Reddy and Chinthamreddy [115] studied the migration of hexavalent chromium, $\mathrm{Cr}$ (VI), nickel, $\mathrm{Ni}(\mathrm{II})$, and cadmium, $\mathrm{Cd}$ (II), in clayey soils that contain different reducing agents under an induced electric potential. They conducted benchscale electrokinetic experiments using two different clays, kaolin and glacial till, both with and without a reducing agent. The reducing agent used was either humic acid, ferrous iron, or sulfide, in a concentration of $1,000 \mathrm{mg} \mathrm{kg}^{-1}$. They spiked the soils with $\mathrm{Cr}$ (VI), $\mathrm{Ni}$ (II), and $\mathrm{Cd}$ (II) in concentrations of 1000,500 and $250 \mathrm{mg} \mathrm{kg}^{-1}$, respectively, and tested under an induced electric potential of $1 \mathrm{~V} \mathrm{DC} \mathrm{cm}{ }^{-1}$ for duration of over 200 hours. Their study found that the reduction of chromium from $\mathrm{Cr}(\mathrm{VI})$ to $\mathrm{Cr}$ (III) occurred prior to electrokinetic treatment and the extent of this $\mathrm{Cr}(\mathrm{VI})$ reduction was found to be dependent on the type and amount of reducing agents present in the soil. The maximum reduction was found to be occurred in the presence of sulfides, while the minimum reduction was found to be occurred in the presence of humic acid. Their study concluded that significant removal of the contaminant from the soils was not achieved and suggested additional research to determine strategies by which contaminant migration may be enhanced and ultimately lead to significant contaminant removal. Ricart et al. [116] investigated 
the feasibility of electrokinetic remediation for the restoration of polluted soil with organic and inorganic compounds had been development and evaluated using a model soil sample. They prepared model soil was prepared with kaolinite clay artificially polluted in the laboratory with chromium ( $\mathrm{Cr}$ ) and an azo dye: Reactive Black 5 (RB5). They focused on the electromigration of $\mathrm{Cr}$ in a spiked kaolinite sample in alkaline conditions. Despite of the high $\mathrm{pH}$ registered in the kaolinite sample (around $\mathrm{pH}$ 9.5), they reported that $\mathrm{Cr}$ migrated towards the cathode and it was accumulated in the cathode chamber forming a white precipitate. The removal was not complete, and only $23 \%$ of the initial $\mathrm{Cr}$ was retained into the kaolinite sample close to the cathode side. They also reported that the electrokinetic treatment of a kaolinite sample polluted with both $\mathrm{Cr}$ and RB5 yielded very good results. The removal of $\mathrm{Cr}$ was improved compared to the experiment where $\mathrm{Cr}$ was the only pollutant, and RB5 reached a removal as high as $95 \%$. RB5 was removed by electromigration towards the anode, where the dye was degraded upon the surface of the electrode by electrochemical oxidation. Chromium $(\mathrm{Cr})$ was transported towards the cathode by electromigration and electro-osmosis. The concluded that the interaction among RB5 and $\mathrm{Cr}$ into the kaolinite sample prevented premature precipitation and allow $\mathrm{Cr}$ to migrate and concentrate in the cathode chamber. The removal of $\mathrm{PAH}$ and metal contaminants from a former manufactured gas plant polluted soil was studied by Reddy et al. [117] and found that the removal is influenced by the type of flushing solution and application of voltage gradient. Igepal surfactant was shown to remove PAHs, while EDTA chelant was shown to remove heavy metals. Sequential application of surfactant and chelant removed both PAHs and heavy metals present in the soil and the efficacy of the process depends on the order of flushing. Application of voltage gradient is found to retard the removal of PAHs and enhance the removal of metals from the soil. Their experiments conducted only for a short duration and suggested to run the experiments for longer duration to establish this as a potent technology for the remediation of soil contaminated by mixed wastes. The study suggested that soil composition can have a profound effect on the contaminant removal; therefore, site-specific soil investigations must be conducted to develop sequential process that will be effective to remove mixed contaminants from the soil.

It is apparent to say that enhanced electrokinetic removal technology has been more effective in removing heavy metals from low permeability soils compared to unenhanced electrokinetic removal technology as the enhanchment agents eliminate the $\mathrm{pH}$ jump topwards the cathode region and be able to break the organometalic complexes in samples where organic matters are present. EDTA, a chelating agent that is readily available and environmentally benign and does not interact with soils, seems to be the best enhancing agent, especially to break the organometalic complexes. Many of the chelating agents other than EDTA are ionic and can, in principle, be introduced into the soil by ionic migration. Allen and Chen [48] have shown that EDTA is an excellent solubilizing agent for many metals including $\mathrm{Pb}$ and $\mathrm{Zn}$. It is of interest that EDTA has been used medically to promote removal of lead from the human body and also as an additive to render floor polishes with zinc binders amenable to detergent washing [41].

EDTA is a tetraprotic acite abbreviated as $\mathrm{H}_{4} \mathrm{Y}$ where $\mathrm{Y}$ denotes the ethylenediaminetetraacetate ion EDTA ${ }^{4-}$. It is slightly solution in water and the four stepwise dissociation constants of the parent acid to yield $\mathrm{H}_{3} \mathrm{Y}^{-}, \mathrm{H}_{2} \mathrm{Y}^{2-}, \mathrm{HY}^{3-}$ and $\mathrm{Y}^{4-}$ ions are $1.00 \times 10^{-2}, 2.16 \times 10^{-3}, 6.92 \times 10^{-7}$ and $5.50 \times 10^{-11}$, respectively [48]. It implies that $\mathrm{H}_{2} \mathrm{Y}^{2-}$ and $\mathrm{HY}^{3-}$ species are major EDTA anions adsorbed [107]. Each EDTA ${ }^{4-}$ ion can attach to a metal ion at six different sites since each of four acetate groups and the two nitrogen atoms have free electron pairs available for coordinate bond formation as shown in Fig. 3 [118]. 


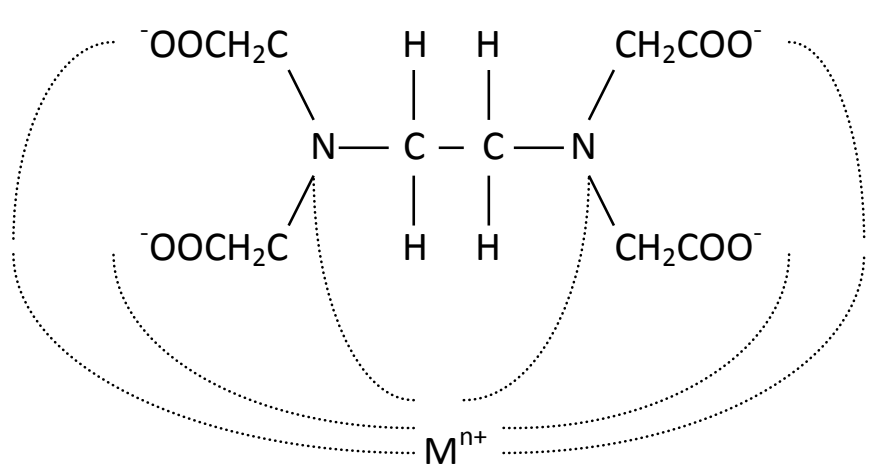

Fig. 3. Configuration of metal-EDTA complexes

Unless the $\mathrm{pH}$ is very high, the EDTA will not be completely deprotonated. In fact, this is the reason for the high solubility of metal-EDTA complexes. The complexation of metals by EDTA is dependent on $\mathrm{pH}$. With a metal ion $\mathrm{M}$, it can form a complex $\mathrm{MY}$, a protonated complex $\mathrm{MHY}$, a hydro complex $\mathrm{MY}(\mathrm{OH})_{n}$ and a mixed complex of the form MYX where $\mathrm{X}$ is a unidentate ligand.

\section{Field Applications}

In most practical applications of electrokinetics, the anodes are iron or aluminum rods and the cathodes are steel tubes. Sometimes graphite electrodes are also used for both anodes and cathodes. Lageman et al. [119] reported the results of field applications in the Netherlands. These studies demonstrated about $60 \%$ of $\mathrm{Zn}$ removal at a concentration of $70 \mu \mathrm{g} \mathrm{g}^{-1}$ from sandy clay soils; $80 \%$ of As removal at a concentration of $90 \mu \mathrm{g} \mathrm{g}^{-1}$ from heavy clayey soils and $75 \% \mathrm{pb}$ removal at a concentration of $340 \mathrm{~g} \mathrm{~g} \mathrm{~g}^{-1}$ from dredged sediment. The energy expenditure ranged from 60 to $220 \mathrm{kWh} \mathrm{m}^{-3}$ of soil processed. Banerjee et al. [120] applied the electrokinetic extraction process in conjunction with the pump-and-treat method in a abandoned industrial hard-chrome plating facility superfund site in Corvallis, Oregon, USA. Their study demonstrated that chromium removal slightly increased, but they didn't provide any numerical value of removal efficiency. They primarily concluded that ion migration plays a significant role in the decontamination process. In another field study conducted at Stadskanaal, The Netherlands [121], it is reported that at an energy expenditure of $20 \mathrm{kWh} \mathrm{m}^{-3}$ of soil, $\mathrm{Pb}$ concentration reduced to $120 \mathrm{mg} \mathrm{kg}^{-1}, \mathrm{Cd} 150 \mathrm{mg} \mathrm{kg}^{-1}$, and $\mathrm{Zn} 320 \mathrm{mg} \mathrm{kg}^{-1}$; at $65 \mathrm{kWh} \mathrm{m}^{-3}$ of soil, $\mathrm{Pb}$ concentration reduced to $90 \mathrm{mg} \mathrm{kg}^{-1}, \mathrm{Cd} 50 \mathrm{mg} \mathrm{kg}$, and $\mathrm{Zn} 120 \mathrm{mg} \mathrm{kg}^{-1}$; and at $180 \mathrm{kWh} \mathrm{m}^{-3}$ of soil, $\mathrm{Pb}$ and $\mathrm{Zn}$ concentrations reduced to less than $10 \mathrm{mg} \mathrm{kg}^{-1}$ and Cd less than $2 \mathrm{mg} \mathrm{kg}^{-1}$. In all cases the initial concentrations of $\mathrm{Pd}, \mathrm{Cd}$ and $\mathrm{Zn}$ were $210 \mathrm{mg} \mathrm{kg}^{-1}, 300 \mathrm{mg} \mathrm{kg}^{-1}$, and $480 \mathrm{mg} \mathrm{kg}^{-1}$, respectively. However, a number of problems not encountered in the laboratory studies arose in the field trails, e.g., presence of unexpected large objects $(>10 \mathrm{~cm})$ buried in the soil.

\section{Summary and Recommendation}

An overview and concept of electrokinetic extraction processes and their potential applications in geotechnical and geoenvironmental engineering have been reviewed and presented. Historically, the success of electrokinetics in soil restoration and decontamination in terms of inorganic contaminants (i.e. heavy metals) has demonstrated its ability to be one of the most cost effective and viable in-situ remediation processes compared to the conventional remediation technologies such as soil washing, ligand extraction, vacuum extraction, thermal desorption, hydraulic fracturing, biotreatment, immobilization by encapsulation, and placement of barrier 
systems. Based on the literature review and researches, it is obvious that the field application of electrokinetic technology to remediate heavy metal contaminated soils /sediments is very limited and site specific. Additional laboratory studies and more pilot- and full-scale information from field applications are critical to the further understanding of the technology and to customize the process in different field conditions.

\section{References}

[1] M. A. Karim, L. I. Khan, Soil Sediment Contam. 20(7) (2011) 857-875.

[2] R. J. Hunter, Zeta potential in colloid science, Principles and applications, Academic Press: London (1982).

[3] J. K. Mitchell, A. T. Yeung, Transport. Res. Rec. 1288 (1990) 1-9.

[4] J. M. Dzenitis, Environ. Sci. Tehnol. 31 (1997) 1191-1197.

[5] J. Q. Shang, Canadian Geotech. J. 34(2) (1997) 305-314.

[6] A. T. Yeung, T. B. Scott, S. Gopinath, R. M. Menon, C.N. Hsu, Geotech. Test. J. 20(2) (1997) 199-210.

[7] A. T. Yeung, S. Datla, Canadian Geotech. J., 32(4) (1995) 569-583.

[8] A. N. Alshawabkeh, Ph.D. Dissertation, Louisiana State University, (1994) 376.

[9] A. N. Alshawabke, Y. B. Acar, Preprint of Extended Abstract, I\&EC Special Symposium, the American Chemical Society, Atlanta, GA, September 19-21 (1994).

[10] S. Datla, A. T. Yeung, Proceedings of $8^{\text {th }}$ International conferenceof the International Association for Computational Method and Advances in Geomechanics, The Netherlands, 1994, p. 1043-1048.

[11] G. R. Eykholt, R. E. Daniel, J. Geotech. Eng. 120(5) (1994) 797-815.

[12] A. T. Yeung, J. Non-Equil. Thermody. 15(3) (1990) 247-267.

[13] A. T. Yeung, J. Adv. Porous Media 2 (1994) 309-395.

[14] A. T. Yeung and J. K. Mitchell, J. Geotechnique 43(1) (1993) 121-134.

[15] J. J. Horng, Ph.D. Dissertation, Department of Civil Engineering, University of Washington, USA (1993).

[16] J. K. Mitchell, J. Geotechnique 41(3) (1991) 299-340.

[17] J. K. Mitchell, Fundamentals of soil behavior, $2^{\text {nd }}$ ed., Wiley \& Sons, New York, 1993.

[18] Y. B. Acar and J. Hamed, Transport. Res. Rec. 1312 (1991) 152-161.

[19] S. Laursen, Ph.D. Dissertation, Denmark Technical University, Denmark (1991).

[20] Y. B. Acar, R. J. Gale, G. Putnam, and J. Hamed, in Proceedings of the $2^{\text {nd }}$ International Symposium on Environmental Geotechnology, Shanghai, China, Hsai-Yang Fang, Sibel Pamukcu, Eds., Envo Pub. Co., Bethlehem, PA, USA, 1989, p. 25-38.

[21] Y. B. Acar, R. J. Gale and G. Putnam, J. Environ. Sci. Heal. A 25(6) (1990) 687-714.

[22] Y. B. Acar, A. N. Alshawabkeh and R. J. Gale, Waste Manage. 13 (1993) 141-151.

[23] Y. B. Acar, R. J. Gale, A. N. Alshawabkeh, R. Marks, S. Puppala, M. Bricka and R. Parker, J. Hazard. Mater. 40(2) (1995) 117-137.

[24] M. Y. Corapcioglu and A. T. Yeung, Technical Completion Report Submitted to Advanced Technology Program, Texas Higher Education Coordinating Board, October 1994.

[25] A. T. Yeung, G. T. Darilek and M. Y. Corapcioglu, J. Civil Eng. 66(3) (1996) 23.

[26] G. T. Darilek, M. Y. Corapcioglu and A. T. Yeung, J. Environ. Eng.-ASCE 122(6) (1996) 540-544.

[27] G. T. Darilek, M. Y. Corapcioglu and A. T. Yeung, Proc. Geosynthetics '95, Nashville, Tennessee, 2 (1995) 539-549.

[28] G. T. Darilek, M. Y. Corapcioglu and A. T. Yeung, Emerg. Technol. 1(2) (1994) 1-4.

[29] A. Czediwoda, H. Stichnothe and A. Schonbucher, in Contaminated Soil '95, Proceedings of the Fifth International FZK/TNO Conference on Contaminated Soil, Maastricht, The 
Netherlands, W. J. Van Den Brink, R. Bosman, F. Arendt, Eds., Kliwer Academic Publishers, Dordrecht, The Netherlands, 1995, p. 1181-1182.

[30] A. T. Yeung, Hong Kong Engineer 21(11) (1993) 25-30.

[31] Y. B. Acar, J. Hamed, R. J. Gale and G. Putnam, Transp. Res. Record 1288 (1990) 23-34.

[32] A. T. Yeung, Geotechnical News, 13(3) (1995) 25-28.

[33] J. K. Mitchell, A. T. Yeung, Transp. Res. Record 1288 (1990) 1-9

[34] J. T. Hamed, Ph.D. Dissertation, Department of Civil \& Environmental Engineering, Louisiana State University, (1990) 200.

[35] R. F. Probstein and R. E. Hicks, Science 260 (1993) 498-504.

[36] Y. B. Acar and A. N. Alshawabkeh, Environ. Sci. Technol. 27(13) (1993) 2638-2647.

[37] L. I. Khan, Ph.D. Dissertation, Department of Civil Engineering, Lehigh University, Bethelham, PA, USA (1991).

[38] R. E. Hicks and S. Tondorf, Environ. Sci. Technol. 28(12) (1994) 2203-2210.

[39] M. A. Karim and L. I. Khan, Environ. Technol. (2012), DOI:10.1080/09593330.2012.665493

[40] M. Kubal and T. Machula, Separ. Sci. Technol. 33(13) (1998) 1969.

[41] S. H. Joseph, R. Wong, R. E. Hicks and R. F. Probstein, J. Hazard. Mater. 55(1-3) (1997) 61-79.

[42] S. K. Puppala, A. N. Alshawabkeh, Y. B. Acar, R. J. Gale and M. Bricka, J. Hazard. Mater. 55 (1997) 203-220.

[43] J. S. H. Wong, R. E. Hicks and R. F. Probstein, J. Hazard. Mater. 55 (1996) 61-79.

[44] A. T. Yeung, C. Hsu and R. M. Menon, J. Hazard. Mater. 55 (1996) 221-237.

[45] M. M. Rahman, M.Sc. Thesis, Dept. of Civil \& Environmental Engineering, Cleveland State University, OH, USA (1996).

[46] S. K. Puppala, M.Sc. Thesis, Louisiana State University (1994) 260.

[47] A. P. Shapiro and R. F. Probstein, Environ. Sci. Technol. 27(2) (1993) 281-291.

[48] H. E. Allen and P. H. Chen, Environ. Prog. 12(4) (1993) 284-293.

[49] R. W. Peters and L. Shem, ASCE Symposium Seroes 509, American Chemical Society, Washington, D.C., (1992) 70-84.

[50] Y. B. Acar, H. Li, H. and R. J. Gale, ASCE J. Geotech. Eng. 118(11) (1992) 1837-1851.

[51] J. Apatoczky, M.Sc. Thesis, Department of Civil Engineering, Lehigh University, USA (1992).

[52] S. Pamucku, L. I. Khan and H. Y. Fang, Transport. Res. Rec. 1288 (1990) 41-46.

[53] A. N. Alshawabkeh and Y. B. Acar, J. Environ. Sci. Heal. A 27(7) (1992) 1835-1861.

[54] A. N. Alshawabkeh and Y. B. Acar, J. Geotech. Eng. 122(3) (1996) 186-196.

[55] M. Z. Sengun, R. E. Hicks and R. F. Probstein, J. Environ. Sci. Heal. A 29(9) (1994).

[56] A. P. Shapiro, Ph.D. Dissretation, Department of Mechanical Engineering, Massachusetts Institute of Technology (MIT), MA, USA (1990).

[57] R. A. Jacobs and R. F. Probstein, AlChE J, 42(6) (19960 1685-1696.

[58] B. S. Haran, B. N. Popov, G. Zheng and R. E. White, J. Haz. Mat. 55 (1996) 93-108.

[59] R. A. Jacobs, M. Z. Sengun, R. E. Hicks and R. F. Probstein, J. Environ. Sci. Heal. A 29(9) (1994) 1933-1955.

[60] J. Yu and I. Neretnieks, J. Chem. Eng. Sci. 51(19) (1996) 4355-4368.

[61] D. J. Wilson, J. M. Rodriguez-Maroto and C. Gomez-Lahoz, Sep. Sci. \& Tech. 30(15) (1995) 2937-2961.

[62] B. A. Sengun and C. J. Brunell, J. Environ. Eng.-ASCE 118(1) (1992) 84-100.

[63] Y. S. Choi and R. Lui, J. Differ. Equations 108 (1994) 424-437.

[64] Y. S. Choi and R. Lui, Arch. Ration. Mech. An. 130 (1995) 315-342.

[65] Y. S. Choi and R. Lui, J. Hazard. Mater. 44 (1995) 61-75.

[66] Y. S. Choi and R. Lui, J. Differ. Equations 116 (1995) 306-317.

[67] Y. S. Choi and Y. Xun, J. Appl. Math. 51 (1993) 251-267.

[68] Y. S. Choi and K. Y. Chan, J. Nonlinear Anal. 18(4) (1992) 317-331. 
[69] Y. S. Choi and K-Y. Chan, J. Electroanal. Chem. Interf. Electrochem. 334 (1992) 13-23.

[70] Y. S. Choi and K. Y. Chan, J. Math. Comput. Simul. 34 (1992) 101-112.

[71] Y. S. Choi, R. Lui and Y. Xun, J. Appl. Math. 52 (1994) 105-122.

[72] A. Wilkowe, M.Sc. Thesis, Department of Civil Engineering, Lehigh University, USA (1992).

[73] K. Euhee, Ph. D. Dissertation, University of Connecticut, USA (1995).

[74] J. Q. Shang, K. Y. Lo and R.M. Quigley, Can. Geotech. J. 31 (1994) 624-636.

[75] Y. Xun, Ph.D. Dissertation, University of Connecticut, USA (1992).

[76] Y. Xun, Quart. Appl. Math. 53(3) (1995) 507-525.

[77] C. D. Shackelford, Environmental Geotechnics, Proceedings of the Second International Congress on Environmental Geotechnics, Vol. 3, Osaka, Japan, 5 - 8 November 1996, p 13751404.

[78] Y. B. Acar and A. N. Alshawabkeh, J. Geotech. Eng. 122(3) (1996) 173-185.

[79] J. T. Hamed, Y. B. Acar, and R. J. Gale, J. Geotech. Eng. 117(2) (1991) 241-271.

[80] S. Pamukcu, A. Weeks, A. and J. K. Wittle, J. Hazard. Mater. 55(1-3) (1997) 305-318.

[81] S. Pamukcu and J. K. Wittle, Environ. Prog. 11(3) (1992) 241-250.

[82] G. R. Eykholt, Ph.D. Dissertation, Department of Civil Engineering, University of Texas at Austin, Texas, USA (1992).

[83] A. T. Yeung, S. M. Sadek and J. K. Mitchell, Geotech. Test. J. 15(3) (1992) 207-216.

[84] H. K. Hansen, L. M. Ottosen, B. MK. Kliem and A. Villumsen, J. Chem. Technol. Biotechnol. 70 (1997) 67-73.

[85] H. K. Hansen, L. M. Ottosen, B. MK. Kliem and A. Villumsen, Separ. Sci. Technol. 32(15) (1997) 2425-2444.

[86] D. J. Wilson, J. M. Rodriguez-Maroto and C. Gomez-Lahoz, Separ. Sci. Technol. 30(16) (1995) 3111-3128.

[87] Z. Li, J. W. Yu, I. Neretnieks J. Hazard. Mater. 55(1-3) (1997) 295-304.

[88] Z. Li, J. W. Yu, I. Neretnieks, J. Contam. Hydrol. 22 (1996) 241-253.

[89] Z. Li, J. W. Yu, I. Neretnieks, J. Environ. Sci. Heal. 32(2) (1996).

[90] L. I. Khan, M. S. Alam, J. Environ. Eng.-ASCE 120(6) (1994) 1524-1545.

[91] G. P. Korfiatis, L. N. Reddi, B. Montanti, Transport. Res. Rec. 1288 (1990) 35-40.

[92] H. K. Hansen, Ph.D. Dissertation, Department of Physical Chemistry, The Technical University of Denmark (1995).

[93] J. T. Hamed, A. Bhadra, J. Hazard. Mater. 55(1-3) (1997) 279-294.

[94] J. Q. Shang, Can. Geotech. J. 34(4) (1997).

[95] J. M. Dzenitis, J. Electrochem. Soc. 144(4) (1997) 1317-1322.

[96] M. Penn, Proceedings British Geotechnical Society Young Engineers Symposium, Oxford, UK, 1-3 (1996).

[97] T. Grundl, C Reese, J. Hazard. Mater. 55 (1997) 187-201.

[98] J. Q. Shang, K. Y. Lo and I. I. Inculet, J. Environ. Eng.-ASCE 121(3) (1995) 243-248.

[99] R. Sri Ranjan, T. Karthigesu, Can. Geotech. J. 33(3) (1996) 504-509.

[100] K. R. Reddy, U. S. Parupudi, S. N. Devulapalli, C. Y. Xu, J. Hazard. Mater. 55 (1997) 135-158.

[101] C. Cameselle, K. R. Reddy, Electrochim. Acta 86 (2012) 10-12.

[102] K. R. Reddy, K. Maturi, C. Cameselle, J. Environ. Eng.-ASCE 135(10) (2009) 989-998.

[103] A. T. Yeung, C. Hsu, R. M. Menon, J. Geotech. Eng. 122(8) (1996) 666-673.

[104] A. P. Shapiro, P. C. Renaud, R. F. Probstein, Physicochem. Hydrodyn. 11(5/6) (1989) 785-802.

[105] C. D. Cox, M. A. Shoesmith, M. M. Ghosh, Environ. Sci. Technol. 30(6) (1996) 1933-1938.

[106] W. D. Ellis, T. R. Fog, A. N. Tafuri, Proceedings of the $12^{\text {th }}$ Annual Research Symposium: Land Disposal, Remediation Action, Incineration and Treatment of Hazardous Waste, (1986) 201207.

[107] C. P. Huang, E. A. Rhoads, O. J. Hao, Water Res. 22(8) (1988) 1001-1009. 
[108] J. K. Klewick, J. J. Morgan, Environ. Sci. Technol. 32(19) (1998) 2916-2922.

[109] C. S. McArdell, A. T. Stone, J. Tian, Environ. Sci. Technol. 32(19) (1998) 2923-2930.

[110] A. P. Davis, I. Singh, J. Environ. Eng.-ASCE 121(2) (1992) 174-185.

[111] S. Amrate, D. E. Akretche, C. Innocent, P. Seta, Sci. Total Environ. 349(1-5) (2005) 56-66.

[112] K. R. Reddy, S. Danda, P. Saichek, J. Environ. Eng.-ASCE 130(11) (2004) 1357-1366.

[113] A. T. Yeung, M. Chung, M. Y. Corapcioglu, W. M. Stallard, In Geoenvironment 2000: Characterization, Containment, Remediation, and Performance in Environmental Geotechnics, Geotechnical Special Publication (GSP) No. 46, Vol. 2, Yalcin B. Acar, David E. Daniel, Eds., American Society of Civil Engineers, New York, NY, USA, 1995, p. 1564-1575.

[114] Y. B. Acar, J. T. Hamed, A. N.Alshawabkeh, R. J. Gale, J. Geotechnique 44(3) (1994) 239-254

[115] K. R. Reddy, S. Chinthamreddy, Waste Manage. 19 (1999) 269-282.

[116] M. T. Ricart, M. Pazos, S. Gouveia, C. Cameselle, M. A. Sanroman, J. Environ. Sci. Heal. A 43(8) (2008) 871-875.

[117] K. R. Reddy, C. Cameselle and P. Ala J. Appl. Electrochem. 40 (2010) 1269-1279.

[118] A. T. Yeung, C. Hsu and R. M. Menon, J. Hazard. Mater. 55 (1996) 221-237.

[119] R. Lageman, P. Wieberen and S. Geert, Chem. Ind.-London, 18 (1989) 585-590.

[120] S. Banerjee, J. J. Horng, J. F. Ferguson, Transp. Res. Record 1312 (1991)167-174.

[121] R. Lageman, Environ. Sci. Technol. 27(13) (1993) 2648-2650.

(C) 2014 by the authors; licensee IAPC, Zagreb, Croatia. This article is an open-access article distributed under the terms and conditions of the Creative Commons Attribution license (http://creativecommons.org/licenses/by/3.0/) (cc)) Br 